\title{
Synchrotron single-crystal diffraction for chemistry and materials: new developments
}

\author{
$\underline{\text { William Clegg }}$
}

Chemistry, School of Natural and Environmental Sciences, Newcastle University, Newcastle upon Tyne NE1 7RU, UK.

\section{E-mail: bill.clegg@ncl.ac.uk}

Prior to the 1990s there were no dedicated single-crystal diffraction beamlines for use by chemists and materials scientists; limited access was available to multi-purpose beamlines used also, and in most cases predominantly, for powder diffraction and/or spectroscopic techniques, along with some minor use of macromolecular crystallography beamlines. The design, construction, and commissioning of Station 9.8 at Daresbury Laboratory's Synchrotron Radiation Source (SRS) ${ }^{1}$ thus began what is now a rich though still brief 20 -year history of bringing the advantages of synchrotron radiation to the community of chemical crystallographers familiar with this key technique in a standard local laboratory setting. The advantages derive from the special properties of synchrotron radiation, principally its high intensity, excellent collimation, and available range of wavelengths.

While the UK led the way, initially at SRS with Station 9.8 and its later more modestly configured Station 16.2SMX, the rapid uptake and exploitation of the new opportunities prompted similar development of dedicated and optimised single-crystal diffraction beamlines elsewhere, notably at ALS, ${ }^{2}$ together with enhancement of single-crystal diffraction facilities on shared beamlines such as those at ESRF, APS, and Soleil. With the closure of SRS, a new UK beamline (I19) was designed and constructed at Diamond Light Source (DLS), beginning operation in $2008 .^{3}$ This has recently undergone a major upgrade. ${ }^{4}$

These beamlines have been used for structural studies across all branches of organic, inorganic, materials, and pharmaceutical chemistry, and have played a vital role in the investigation of large-scale supramolecular assemblies and extended framework structures, with applications in gas and energy storage among other important modern research areas.

Our own use has included the elucidation of structures displayed on journal front covers, some unusual structural features such as highly strained metallated aromatic molecules, and a natural product with exceptional antibiotic properties. Recent achievements include the successful development of remote access operation of DLS beamline I19, ${ }^{5}$ which should now become the standard form of usage of the beamline, bringing many advantages. Examples will be shown, along with a summary of the history and new aspects.

\section{References}

1. Cernik RJ, Clegg W, Catlow CRA, Bushnell-Wye G, Flaherty JV, Greaves GN, Burrows I, Taylor DJ, Teat SJ, Hamichi M, A new high-flux chemical and materials crystallography station at the SRS Daresbury. 1. Design, construction and test results, J. Synchrotron Rad., 1997, 4, 279-286.

2. McCormick LJ, Giordano N, Teat SJ, Beavers CM, Chemical crystallography at the Advanced Light Source, Crystals, 2017, 7, 382.

3. Nowell H, Barnett SA, Christensen KE, Teat SJ, Allan DR, I19, the small-molecule single-crystal diffraction beamline at Diamond Light Source, J. Synchrotron Rad., 2012, 19, 435-441.

4. Allan DR, Nowell H, Barnett SA, Warren MR, Wilcox A, Christensen J, Saunders LK, Peach A, Hooper MT, Zaja L, Patel S, Cahill L, Marshall R, Trimnell S, Foster AJ, Bates T, Lay S, Williams MA, Hathaway PV, Winter G, Gerstel M, Wooley RW, A novel dual air-bearing fixed- $\chi$ diffractometer for small-molecule single-crystal X-ray diffraction on beamline 119 at Diamond Light Source, Crystals, 2017, 7, 336.

5. Johnson NT, Waddell PG, Clegg W, Probert MR, Remote access revolution: chemical crystallographers enter a new era at Diamond Light Source beamline I19, Crystals, 2017, 7, 360. 